\title{
Study of intrauterine fetal death cases in a tertiary care center
}

\author{
Lalita Meena*, Ritu Gupta
}

Department of Obstetrics and Gynecology, Jhalawar Medical College, Jhalawar, Rajasthan, India

Received: 25 December 2019

Revised: 24 January 2020

Accepted: 29 January 2020

\section{*Correspondence:}

Dr. Lalita Meena,

E-mail: lalitameena7777@gmail.com

Copyright: () the author(s), publisher and licensee Medip Academy. This is an open-access article distributed under the terms of the Creative Commons Attribution Non-Commercial License, which permits unrestricted non-commercial use, distribution, and reproduction in any medium, provided the original work is properly cited.

\begin{abstract}
Background: The death of a fetus is a tragic event not only for the parents but also a great cause of stress for the caregiver. It is thus vital to identify specific probable causes of fetal death to determine the risk of recurrence, prevention or corrective action.

Methods: This retrospective observational study was carried out in department of obstetrics and gynaecology, Jhalawar Medical College, Jhalawar, from July 2019 to October 2019. Intrauterine fetal death was confirmed either with ultrasound or on clinical examination. The details of complaints, obstetrics history, examination findings, mode of delivery, fetal outcomes and investigation reports were recorded.

Results: A total of 114 intrauterine fetal deaths were reported amongst 2982 deliveries conducted during the study period. The incidence rate of IUFD was 38.22/1000 live births. $85.96 \%$ deliveries were unbooked. 59.64\% belonged to rural population. $59.64 \%$ fetal deaths occurred in women between 20 to 25 years of age. $45.61 \%$ women were primigravida. $41.2 \%$ IUFD occurred between 26 to 31 weeks of gestation. Among the identifiable cause's hypertensive disorders (23.68) and placental causes (19.29\%) were most common.

Conclusions: Unexplained causes, PIH and abruptio placentae were major causes of IUFD. Majority of fetal wastage can be prevented with universal and improved antenatal care.
\end{abstract}

Keywords: Antenatal care, Gestation, Incidence, Intrauterine fetal death, Pregnancy, Risk factors

\section{INTRODUCTION}

Intrauterine death is one of the unhappy events in the field of obstetrics. It remains one of the areas of obstetrics in which improvements could be made. It is really distressing when it occurs without warning in a pregnancy that has previously entirely normal. It is an important indicator of maternal and perinatal health of a given population. Intrauterine fetal death (IUFD) is the death of a fetus prior to complete expulsion or extraction from the mother of a product of human conception irrespective of the duration of pregnancy and which is not induced termination of pregnancy. ${ }^{1}$ The death is indicated by the fact that after such expulsion or extraction, fetus does not breathe or show any other evidence of life such as beating of heart, pulsation of umbilical cord or definite movement of voluntary muscle. ${ }^{1}$ Defined variously after $20^{\text {th }}$ or $28^{\text {th }}$ weeks of gestation. (The definition of length of gestation varies between countries). The prevalence of IUFD has been decreased in developed countries but it still remains very high in underdeveloped and developing countries. There are so many maternal conditions and diseases that are responsible for poor obstetrical outcomes. The major problem facing the obstetrician is the identification of women at risk; as many cases seem to occur in the absence of recognized risk factors. By proper antenatal check-ups, the high-risk cases associated with poor outcomes can be identified. This study was undertaken to study the maternal, fetal and placental factors associated with intrauterine fetal death. 


\section{METHODS}

This retrospective observational study was carried out in department of obstetrics and gynaecology, Jhalawar Medical College Jhalawar, Rajasthan, India from July 2019 to oct 2019. This study was conducted in several stages including accurate determination of the problem under study, collection, analysis and interpretation of the findings.

\section{Inclusion criteria}

- All the women with gestational period beyond 20 weeks to full term pregnancy having normal/malformed fetus were included in the study. The patients who gave informed consent were included in the study.

\section{Exclusion criteria}

- The records of babies born below 20 weeks of gestation, fetus weighing below $500 \mathrm{gm}$ and twin babies were excluded. Those patients who did not give informed consent were excluded from the study.

Pt was thoroughly interrogated and systematically examined and optimally investigated and all findings were recorded on designed preformed proforma. The patients presented with chief complaints of amenorrhea, labour pains, decreased or loss of fetal movements, history of leaking, bleeding per vagina. The obstetrical history included parity, abortions, stillbirth, neonatal death, lower segment caesarean section (LSCS), preterm delivery, antepartum hemorrhage (APH) or any medical disorder in previous pregnancy. Other history includes menstrual history, past history, personal history, general examination, local examination findings, per vaginal examination, mode of delivery, fetal outcomes, placental examination, and investigation reports. The records of per vaginal findings included bleeding PV, dilatation of the cervix, effacement of the cervix, membrane, presenting part and pelvis. Sociodemographic factors were also included in the study. The parameters of assessment for analysis were maternal age, parity, living is, gestational age, booked or unbooked case and risk factors for IUFD. Data analysis was done. The aim of this study was to determine the incidence, associated maternal risk factors and sociodemographic factors of IUFD. The ethical approval for this study was obtained from the Ethics Committee of Jhalawar Medical College Hospital.

\section{RESULTS}

This study was conducted from July 2019 to October 2019. In the study period there was total 2982 deliveries and among them total number of IUFD was 114. The Incidence of IUFD at our centre was 38.22 per 1000 live birth (Table 1).
Table 1: Total deliveries and total IUFD during the study period.

\begin{tabular}{|ll|}
\hline Total deliveries and total IUFD \\
\hline Total deliveries & 2982 \\
\hline Total IUFD & 114 \\
\hline
\end{tabular}

Table 2: Distribution of cases according antenatal booking.

\begin{tabular}{|lll|}
\hline Antenatal booking & \\
\hline Unbooked & 98 & $85.96 \%$ \\
\hline Booked & 16 & $14.04 \%$ \\
\hline Total IUFD & $\mathbf{1 1 4}$ & $\mathbf{1 0 0 \%}$ \\
\hline
\end{tabular}

There were total 114 IUFD cases in which $98(85.96 \%)$ cases unbooked and $16(14.04 \%)$ cases booked. Even single antenatal visit was included in booked cases. This shows that incidence of IUFD was more in unbooked cases. This also shows the significance of antenatal check-up in reduction of incidence of IUFD (Table 2).

Table 3: Distribution of cases according to living area.

\begin{tabular}{|lll|}
\hline Living area & & \\
\hline Rural & 68 & $59.64 \%$ \\
\hline Urban & 46 & $14.03 \%$ \\
\hline Total & $\mathbf{1 1 4}$ & $\mathbf{1 0 0 \%}$ \\
\hline
\end{tabular}

In this study patients were distributed according to their living area. Most of the patients, $68(59.64 \%)$ belong to rural area and other $16(14.03 \%)$ belong to urban area. This shows that living area also has an impact on incidence of IUFD (Table 3).

Table 4: Distribution of cases according to maternal age.

\begin{tabular}{|lll|}
\hline Age (years) & No. of cases & \% of cases \\
\hline$<20$ & 6 & 5.26 \\
\hline $20-25$ & 68 & 59.64 \\
\hline $26-30$ & 26 & 22.80 \\
\hline $30-35$ & 8 & 7.01 \\
\hline $36-40$ & 5 & 4.38 \\
\hline$>40$ & 1 & 0.91 \\
\hline Total & $\mathbf{1 1 4}$ & $\mathbf{1 0 0}$ \\
\hline
\end{tabular}

Majority of fetal deaths (59.64) occurred in women between 20 to 25 years of age and minority of fetal deaths $(0.91 \%)$ occurred in women above 40 yrs. of age. In India majority of women married in this age group (20-25 years). This shows that incidence of intrauterine fetal death was more in younger age group (Table 4).

The majority $52(45.61 \%)$ of women were primi gravid. $26(22.80 \%)$ women were $2^{\text {nd }}$ gravida, $17(14.91 \%)$ women were $3^{\text {rd }}$ gravida, $15(13.15 \%)$ women were 4 th gravida and $4(3.53 \%)$ women were $5^{\text {th }}$ gravida. Overall 
$62(54.38 \%)$ women were multigravida in this study (Table 5).

Table 5: Distribution of cases according to parity.

\begin{tabular}{|lll|}
\hline Parity & No. of cases & \% of cases \\
\hline G1 & 52 & 45.61 \\
\hline G2 & 26 & 22.80 \\
\hline G3 & 17 & 14.91 \\
\hline G4 & 15 & 13.15 \\
\hline G5 & 4 & 03.53 \\
\hline Total & $\mathbf{1 1 4}$ & $\mathbf{1 0 0}$ \\
\hline
\end{tabular}

Table 6: Gestational age distribution of IUD fetus.

\begin{tabular}{|lll|}
\hline $\begin{array}{l}\text { Gestational age of } \\
\text { IUD fetus in weeks }\end{array}$ & No. of cases & $\%$ of cases \\
\hline $20-25$ & 43 & 37.9 \\
\hline $26-31$ & 47 & 41.2 \\
\hline $32-36$ & 19 & 16.6 \\
\hline$>37$ & 05 & 4.3 \\
\hline Total & $\mathbf{1 1 4}$ & $\mathbf{1 0 0}$ \\
\hline
\end{tabular}

Majority of IUFD, 47 (41.2\%) occurred between 26 to 31 weeks of gestation and only $5(4.3 \%)$ IUFD occurred at 37 weeks of gestation or more. So, most of the babies were preterm. $43(37.9 \%)$ IUFD occurred between 20 to 25 weeks of gestation and $19(16.6 \%)$ IUFD occurred between 32 to 36 weeks of gestation (Table 6).

Table 7: Etiology.

\begin{tabular}{|lll|}
\hline Etiology & No. of cases & \% of cases \\
\hline Unknown & 40 & 35.08 \\
\hline Maternal & & \\
\hline $\begin{array}{l}\text { Pre-eclampsia and } \\
\text { eclampsia }\end{array}$ & 27 & 23.68 \\
\hline Anaemia & 7 & 06.14 \\
\hline Diabetes & 5 & 04.38 \\
\hline Oligohydramnios & 3 & 02.63 \\
\hline Jaundice & 3 & 02.63 \\
\hline Fever & 1 & 00.80 \\
\hline Trauma & 1 & 00.80 \\
\hline Fetal & & \\
\hline Congenital malformation & 2 & 01.75 \\
\hline IUGR & 3 & 02.63 \\
\hline Placental & & \\
\hline Abruptio placenta & 12 & 10.52 \\
\hline Placenta previa & 10 & 08.96 \\
\hline Total & $\mathbf{1 1 4}$ & $\mathbf{1 0 0}$ \\
\hline
\end{tabular}

Majority of $40(35.08 \%)$ IUFD were due to unexplained etiology. IUFD occurred due to preeclampsia-eclampsia, anemia and uncontrolled diabetes in 27 (23.68\%), 7 $(6.14 \%)$ and $5(4.38 \%)$ respectively. IUFD occurred due to oligohydramnios and jaundice in $3(2.63 \%)$ each. Fever and trauma lead to IUFD in $1(0.8 \%)$ each.
Congenital malformation was the cause of IUFD in 2 (1.75\%). IUFD occurred in $12(10.52 \%)$ of abruptio placenta and in $10(8.96 \%)$ of placenta previa (Table 7$)$.

\section{DISCUSSION}

This study consists of 114 IUFD cases amongst 2982 total births. Thus, the incidence of IUFD was 38.22/1000 live births. ${ }^{2-5}$ The incidence of IUFD reported from western countries ranges from $4.7 \%$ to $12.0 \%$. This is lower than that observed in our study. ${ }^{6,7}$ The incidence rate reported from various centers in India is higher 24.4$41.9 \% .^{2-5}$ The reason of higher IUFD at our center is, it being a tertiary care center and all high risk and complicated cases are referred to this center. The other reason could be a high number of unsupervised pregnancy due to various reasons like illiteracy, poverty and the paucity of monitoring facilities in rural areas. Nutritional deficiency and anemia are leading cause of poor pregnancy outcome, the majority of this patients had anemia. The Increased risk of fetal death is present amongst the teenage group and older women. The western studies also show increased risk of IUFD in women over 35 years of age. In this study, however, the fetal deaths were more in the age group of 20-30 years. This is because most of the women in India complete the family before 35 years of age. Increased risk of IUFD is seen amongst primigravidas. The incidence is higher amongst women with minimal or no antenatal care. This is also reflected in our study where the rates were highest amongst the unbooked pregnancies. The incidence of APH in this study was $22(19.29 \%)$. The incidence of intrauterine growth retardation in our study was 3 $(2.63 \%)$. The other studies have reported the incidence from $2.2 \%$ to $18.4 \%$. $23.68 \%$ cases of IUFD were due to hypertension related causes like pre-eclampsia and eclampsia which is similar to that reported in other studies. ${ }^{8}$ The incidence of congenital malformation was $1.75 \%$ which was contrast to that reported from other studies. ${ }^{8}$ Identification of high risk cases and their timely referral to higher centers may save the baby. Patient compliance is important in reducing most of these preventable foetal losses. However unexplained cause of IUFD seen in $40(35.08 \%)$ cases. In case of unexplained IUFD fetal autopsy, placental and membrane examination could be helpful for finding out causes and enhance it Pt. should be counselled in a positive way to explore unexplained IUFD.

\section{CONCLUSION}

Hypertensive disorder of pregnancy, anaemia, APH, congenital anomaly and unexplained cause were leading causes of IUFD. Majority of women who had IUFD were unbooked and had emergency admission and had not received adequate antenatal care and belongs to rural area. The associated risk factors in a community seems to be preventable, hence authors should pay attention to health education with emphasis on antenatal care and its benefit, improved pre-conceptional environment, 
nutrition, micronutrient status especially iron and folic acid intake.

Funding: No funding sources Conflict of interest: None declared

Ethical approval: The study was approved by the Institutional Ethics Committee

\section{REFERENCES}

1. Cunningham F, Kenneth J, Steven L, Bloom Catherine Y, Dashe SJS, Barbara L, Cet al. Preconceptional and prenatal care. Williams obstetrics. $25^{\text {th }}$ edition. McGraw-Hill Education; 2014:645.

2. Patel S, Thaker R, Shah P, Majumder S. Study of causes and complications of intra uterine fetal death (IUFD). Int J Reprod Contracept Obstet Gynecol. 2014;3(4):931-5.

3. Mathuriya G, Bunkar N. Evaluation of intrauterine foetal death at tertiary care center. Inter J Medical Sci Res Prac. 2015;2(3):139-42.

4. Sharma S, Sidhu H, Kaur S. Analytical study of intrauterine fetal death cases and associated maternal conditions. Int J Appl Basic Med Res. 2016;6(1):113.

5. Dasgupta S, Saha I, Mandal AK. A study on profile of stillbirths. J Indian Med Assoc. 1997;95(6):175-8.

6. Hovatta O, Lipasti A, Rapola J, Karjalainen O. Causes of stillbirth: a clinicopathological study of 243 patients. Br J Obstet Gynaecol. 1983;90(8):6916.

7. Machin GA. A perinatal mortality survey in southeast London, 1970-73: pathological findings in 726 necropsies. J Clin Pathol. 1975;28(6):428-34.

8. Misra PK, Thakur S, Kumar A, Tandon S. Perinatal mortality in rural India with special reference to high risk pregnancies. J Trop Pediatr. 1993;39(1):41-4.

Cite this article as: Meena L, Gupta R. Study of intrauterine fetal death cases in a tertiary care center. Int J Reprod Contracept Obstet Gynecol 2020;9:1255-8. 